\title{
$\sigma^{\circ}$ III CONEMP \\ III CONGRESSO NACIONAL

\section{VIABILIDADE DE INVESTIMENTO: UM ESTUDO PARA A IMPLANTAÇÃO DE UM SILO EM UMA COOPERATIVA AGRÍCOLA}

\author{
Congresso Nacional Online de Empreendedorismo, 3a edição, de 06/12/2021 a 08/12/2021
} ISBN dos Anais: 978-65-81152-30-7

MASSON; Fábio Junior ${ }^{1}$, SILVA; Leonardo Kaiber Moraes Alves da ${ }^{2}$, ALVES; Ranieri ${ }^{3}$, SERRA; Adriano ${ }^{4}$, LIMA; Amanda Camerini ${ }^{5}$

\section{RESUMO}

O setor da agricultura representa uma boa parcela do PIB brasileiro, sendo de suma importância o investimento em tecnologias e demais utensílios para continuarsendo uma das grandes potências nesse meio. O Brasil exporta grandes quantidadesde alimento para o restante do mundo e vem alcançando recordes de exportações nos últimos anos. As cooperativas agrícolas buscam atender às demandas sociais e econômicas desuas comunidades, mas, para que se alcance o resultado esperado, se faz necessáriouma relação de confiança entre os cooperados, a fim de possibilitar elevar aprodutividade e participar com competitividade na comercialização dos produtos. O objetivo dessa pesquisa, foi avaliar a viabilidade de implantação de um silo em uma cooperativa agrícola na região do Vale do Ivinhema - Mato Grosso do Sul. Para concluir o trabalho, foi necessário realizar uma pesquisa de campo buscando a coleta de dados referentes as dimensões da área, para projetar a população de atendimento. A pesquisa foi decaráter quantitativo, onde as informações obtidas foram transformadas em números para analisar a viabilidade e potencial de implantação. Para avaliar os dados, foi utilizada a ferramenta Payback, que permitiu calcular o tempo de retorno do investimento, que será no quinto ano de instalação do silo. Também foi identificado que ocorrerá um aumento de $5 \%$ no preço dos insumos para a safra de 2021/2022. Para o ano de 2022, a cooperativa chegará a uma adesão de $66 \%$ no seu atendimento. Diante do exposto, foi possível concluir que a região do Vale do Ivinhemapossui um grande potencial produtivo, tornando viável a implantação de um novo silona cooperativa.

PALAVRAS-CHAVE: Armazenamento, planejamento, potencial 